\title{
Isolation, Characterization and Selection of Rhizobium Strains for Cultivation of Sesbania sp.
}

Md. Zakaria Hasan ${ }^{1 *}$, Mohammad Shah Alam², Musharraf Hossain Mian ${ }^{3}$ and Md. Zahurul Islam ${ }^{4}$

CSISA-CIMMYT, Faridpur Hub ${ }^{1}$

Dept. of Agriculture Extension, Ministry of Agriculture ${ }^{2}$

Dept. of Soil Science, Bangladesh Agricultural University, Mymensingh ${ }^{3}$

Dept. of Soil Science, Bangladesh Institute of Nuclear Agriculture, Mymensingh, Bangladesh $^{4}$

Corresponding author : z.hasan@cgiar.org

\begin{abstract}
The experiment was conducted to isolate Rhizobium form the root nodules of Deshi dhaincha (Sesbania aculeate) and African dhaincha (Sesbania rostrata), characterization of isolates for authentication, testing their performance as the inoculants and selection of better performed strains for future use as biofertilizer. Nineteen rhizobial strains were isolated from root nodule of dhaincha from 5 Agro Ecological Zones (AEZ 9, AEZ 11, AEZ 12, AEZ 13 and AEZ 28) of Bangladesh. The strains were characterized through morphological, biochemical, microscopic and growth observation. Experiment was conducted in bacteriologically controlled condition using sterile sand in plastic pot in glasshouse. Two varieties of Sesbania named Deshi dhaincha and African dhaincha were used as test crop varieties. Five plants were grown in each plastic pot. After 25 days of sowing plants were harvested and data on nitrogen content of shoot, shoot dry weight, root dry weight, nodule number and nodule dry weight of Sesbania cultivars in glass house were collected. Rhizobial inoculation had significant and positive effect on nitrogen content of shoot, shoot dry weight, root dry weight, nodule number and nodule dry weight for both varieties of Sesbania in sterile condition. The strain DhM3 recorded the highest nitrogen content of shoot, shoot dry weight, root dry weight, nodule number and nodule dry weight. The strain DhSk2 ranked second and DhSk4 ranked third in respect of growth, nodulation, nitrogen fixation and biomass production. Therefore, these three strains can be used for Rhizobium inocula production for cultivation of Sesbania but field level extended studies recommended
\end{abstract}

Key words: Dhaincha, AEZ, Rhizobium, Sesbania sp., Nodule and Biofertilizer

\section{Introduction}

Soils with adequate fertility status are essential for crop productivity and sustainability. Leguminous plants proved to be useful tool for improving soil fertility through regenerative means. Leguminous plants in association with Rhizobium can fix significant amount of atmospheric nitrogen from air which contributes to soil nitrogen pool (Jefing et al., 1992). On a global level, annual contribution of biological nitrogen fixation has been estimated about 172 million tons. Legumes contribute about $25 \%$ (33 m tons) of biologically fixed nitrogen, which is slightly less than that supplied to agroecosystems through chemical fertilizers (Azam, 2001; Lshizuka, 1992). Sesbania being potential in nitrogen fixing bacteria is cultivated in Bangladesh. Its inoculation with superior rhizobial strains is essentially required to increase the yield of legumes through nitrogen fixation (Athar, 1998). 
Rhizobium-legume symbiosis can increase yield with subsequent decrease in pollution (Freiberg et al., 1997). Rhizobial isolates vary in their nitrogen fixation potential and in improving the vegetative and reproductive growth of different crops under varying environmental conditions (Shishidu and Pepper, 1990; Gopalakrishnan and Grish, 1999). So, effective nitrogen fixing strains of rhizobia are being developed as inoculant for various legumes (Hardarson, 1993; Brockwell and Bottomely, 1995; Shah et al., 2000). This research was conducted to achieve two major objectives - firstly, isolation and characterization of rhizobia from Deshi and African dhaincha and secondly, the effect of isolated rhizobia inoculants on growth, nodulation and biomass production of Deshi dhaincha (Sesbania aculeata) and African dhaincha (Sesbania rostrata) plants.

\section{Materials and Methods}

Nodules of Sesbania plants were collected from five selected Agro Ecological Zones- AEZ 9: Old Brahmaputra Floodplain (BAU Farm, Mymensingh), AEZ 11: High Ganges River Floodplain (Ishurdi, Pabna), AEZ 12: Low Ganges River Floodplain (Faridpur Sadar), AEZ 13: Ganges Tidal Floodplain (BINA Substation, Satkhira) and AEZ 28; Madhupur Tract (Dhonbari, Tangail). Roots with intact nodules were carried out to BNF (Biological Nitrogen Fixation) Laboratory, Division of Soil Science, Bangladesh Institute of Nuclear Agriculture (BINA), Mymensingh.

Larger, healthy and mature nodules were selected. After separation nodules were washed in running tap water and transferred to sterile vial. Selected nodules were then immersed into $70 \%$ alcohol solution for 30 seconds and in 3\% hydrogen peroxide solution for 3 minutes. Hydrogen peroxide treated nodules were then rinsed with sterile mild hot water for several times. Nodules were then cut transversely with sterile blade and the milky suspension directly from the cut nodule was streaked out on congo red yeast extract mannitol agar (CRYEMA) plates using inoculation needle under laminar flow hood. Plates were incubated for 7 days at $28^{\circ} \mathrm{C}$ temperature.

Colonies were characterized through a systematic series of tests such as cultural tests (i.e. shape, size, opacity, elevation, surface, margin, consistency, emulsifiability, colour odour etc.), microscopic tests (i.e. simple staining, gram staining, motility observation etc.), biochemical tests (i.e. Congo red absorption test, BTB test, Hofer's alkaline broth test etc.) and nodulation tests.

Nodulation capacity of rhizobial isolates were determined by growing plants in plastic buckets containing $2 \mathrm{~kg}$ autoclaved sand (at $20 \mathrm{lbs}$ pressure for 2 hours) in glass houses. Seeds of both Deshi dhaincha (Sesbania aculeata) and African dhaincha (Sesbania rostrata), were rinsed with concentrated Sulphuric Acid (H2SO4) for few seconds and immediately washed thoroughly by distilled water. Prior to sowing, seeds were treated with a thick Rhizobium suspension of each isolate. Ten seeds were planted in each bucket and thinned to keep five plants after germination. Sterilized Jensen's (1942) seedling solution was added to each bucket at one day intervals.

Plants samples were collected from the plastic buckets at 25 days of sowing. From each buckets 3 randomly selected plants were carefully taken out so that no nodule was left in the soil. Roots were washed and the Nodules from the root system of each plant were separately collected and counted. Oven dry weights of nodules were also recorded.

Data obtained from the pot experiment were analyzed statistically by F-test to examine whether treatment effects were significant or insignificant (Gomez and Gomez, 1984). The treatment means were evaluated by Duncan's New Multiple Range Test (DMRT). 


\section{Results and Discussion}

Nineteen rhizobial isolates were obtained from root nodules of Deshi and African dhaincha plants. They were designated as-DhF1, DhF2, DhF3, DhF4, DhM1, DhM2, DhM3, DhM4, DhT1, DhT2, DhT3, DhT4, DhSk1, DhSk2, DhSk3, DhSk4, DhP1, DhP2 and DhP3, respectively. The colony characteristics of isolates did not vary widely. The isolates produced round, whitish, smooth surfaces with entire margin on (CRYEMA) plates.

All the isolates were found short rod in shape, motile in nature and gram negative in reaction. The bacterial isolates did not absorb congo red at young stage but absorbed slightly when cultures became old. All the bacterial isolates produced acid in variable amounts on BTB-YEMA plates. Among the nineteen isolates none had grown on Hofer's alkaline broth.

All the isolates showed good growth at temperature $28^{\circ} \mathrm{C}$ and $32^{\circ} \mathrm{C}$. Most of the isolates grew weakly at $14^{\circ} \mathrm{C}$. At $22^{\circ} \mathrm{C}$ most isolates exhibited medium growth while seven isolates (DhT1, DhT2, DhSk2, DhSk3, DhP1, DhP2 and DhP3) recorded weak growth. All the isolates grew at $38^{\circ} \mathrm{C}$. Only nine isolates (DhF1, DhF2, DhT1, DhT2, DhSk1, DhSk2, DhSk3, DhSk4 and DhP1) showed good growth at $38^{\circ} \mathrm{C}$ while rest ten showed medium growth. Most of the isolates do not grew at $45^{\circ} \mathrm{C}$.

Table 01. Effect of Rhizobium inoculation on nitrogen content of shoot, shoot dry weight, root dry weight, nodule number and nodule dry weight of Sesbania sp

\begin{tabular}{|c|c|c|c|c|c|}
\hline Treatments & $\begin{array}{c}\text { Nitrogen } \\
\text { content }(\%) \text { in } \\
\text { shoot } \\
\end{array}$ & $\begin{array}{c}\text { Shoot dry } \\
\text { weight } \\
\left(\text { mg plant }^{-1}\right) \\
\end{array}$ & $\begin{array}{l}\text { Root dry weight } \\
\left(\mathrm{mg} \mathrm{plant}^{-1}\right)\end{array}$ & $\begin{array}{l}\text { Total nodule } \\
\left(\text { no. }^{\text {plant }}{ }^{-1} \text { ) }\right.\end{array}$ & $\begin{array}{c}\text { Nodule dry weight } \\
\left(\mathrm{mg} \mathrm{plant}^{-1}\right)\end{array}$ \\
\hline \multicolumn{6}{|l|}{ Variety } \\
\hline Deshi dhaincha & $5.84 \mathrm{a}$ & $162.4 \mathrm{a}$ & $45.12 \mathrm{a}$ & $34.33 b$ & $17.85 \mathrm{~b}$ \\
\hline African dhaincha & $4.76 \mathrm{~b}$ & $127.1 \mathrm{~b}$ & $40.63 \mathrm{~b}$ & $36.42 \mathrm{a}$ & $21.07 \mathrm{a}$ \\
\hline Significant level & $1 \%$ & $1 \%$ & $1 \%$ & $5 \%$ & $1 \%$ \\
\hline \multicolumn{6}{|c|}{ Rhizobial inoculation } \\
\hline DhF1 & 4.63hi & $117.70 \mathrm{i}$ & $31.33 \mathrm{gh}$ & $28.00 \mathrm{i}$ & $11.161 \mathrm{~m}$ \\
\hline DhF2 & $4.85 \mathrm{gh}$ & $121.00 \mathrm{i}$ & $27.33 \mathrm{~h}$ & 29.67hi & $10.91 \mathrm{~m}$ \\
\hline DhF3 & $5.04 \mathrm{fg}$ & $141.50 \mathrm{~g}$ & $34.67 \mathrm{fg}$ & $33.17 \mathrm{f}-\mathrm{i}$ & $14.38 \mathrm{j}$ \\
\hline DhF4 & 5.40def & $144.70 \mathrm{fg}$ & $31.33 \mathrm{gh}$ & $33.50 \mathrm{f}-\mathrm{i}$ & $13.63 \mathrm{j}$ \\
\hline DhM1 & $5.71 \mathrm{bcd}$ & $159.00 \mathrm{~d}$ & $47.33 \mathrm{e}$ & $44.50 \mathrm{~b}$ & $21.43 \mathrm{f}$ \\
\hline DhM2 & $5.85 b c$ & $158.30 \mathrm{de}$ & $47.33 \mathrm{e}$ & $38.33 c-f$ & $20.53 \mathrm{~g}$ \\
\hline DhM3 & $6.06 \mathrm{~b}$ & $187.00 \mathrm{a}$ & $62.33 a$ & $52.33 \mathrm{a}$ & $31.62 \mathrm{a}$ \\
\hline DhM4 & $4.93 \mathrm{gh}$ & 157.70de & $45.33 \mathrm{e}$ & $40.67 \mathrm{~b}-\mathrm{e}$ & 19.73gh \\
\hline DhT1 & $4.94 \mathrm{gh}$ & $127.30 \mathrm{~h}$ & $31.00 \mathrm{gh}$ & 29.33hi & 11.771 \\
\hline DhT2 & $5.10 \mathrm{fg}$ & $118.30 \mathrm{i}$ & $29.33 \mathrm{~h}$ & $31.67 \mathrm{ghi}$ & $12.62 \mathrm{k}$ \\
\hline DhT3 & $5.10 \mathrm{fg}$ & $142.00 \mathrm{~g}$ & $38.00 \mathrm{f}$ & $36.33 \mathrm{~d}-\mathrm{g}$ & $18.37 \mathrm{i}$ \\
\hline DhT4 & $4.87 \mathrm{gh}$ & $143.50 \mathrm{fg}$ & $38.33 \mathrm{f}$ & $35.17 \mathrm{efh}$ & $19.32 \mathrm{~h}$ \\
\hline DhSk1 & $5.69 \mathrm{~cd}$ & $175.30 \mathrm{~b}$ & $56.67 \mathrm{bc}$ & $39.17 b-f$ & $27.43 \mathrm{c}$ \\
\hline DhSk2 & $5.82 \mathrm{bc}$ & $157.00 \mathrm{de}$ & $52.17 \mathrm{~cd}$ & $44.00 \mathrm{bc}$ & $22.63 \mathrm{e}$ \\
\hline DhSk3 & $6.08 \mathrm{~b}$ & $166.70 \mathrm{c}$ & $60.00 \mathrm{ab}$ & $37.67 \mathrm{~d}-\mathrm{g}$ & $29.00 \mathrm{~b}$ \\
\hline DhSk4 & 5.24efg & $153.50 \mathrm{e}$ & $49.33 \mathrm{de}$ & $38.67 \mathrm{~b}-\mathrm{f}$ & $25.55 \mathrm{~d}$ \\
\hline DhP1 & $6.58 \mathrm{a}$ & $147.30 \mathrm{f}$ & $45.00 \mathrm{e}$ & $35.67 \mathrm{efg}$ & $26.33 \mathrm{~d}$ \\
\hline DhP2 & $4.37 \mathrm{ij}$ & $169.30 \mathrm{c}$ & $55.33 \mathrm{bc}$ & $42.33 \mathrm{bcd}$ & $25.60 \mathrm{~d}$ \\
\hline DhP3 & $5.55 \mathrm{cde}$ & $161.30 \mathrm{~d}$ & $56.67 \mathrm{bc}$ & $37.33 \mathrm{~d}-\mathrm{g}$ & $27.23 \mathrm{c}$ \\
\hline Control & $4.27 \mathrm{j}$ & $45.67 \mathrm{j}$ & $18.67 \mathrm{i}$ & $0.00 \mathrm{j}$ & $0.00 \mathrm{n}$ \\
\hline Significant level & $1 \%$ & $1 \%$ & $1 \%$ & $1 \%$ & $1 \%$ \\
\hline$C V(\%)$ & 5.52 & 2.73 & 8.33 & 12.39 & 3.60 \\
\hline
\end{tabular}


In a column, figures having similar letter (s) do not differ significantly as per Duncan's Multiple Range Test (DMRT).

Table 02. Interaction effect of Rhizobium inoculation on nitrogen content of shoot, shoot dry weight, root dry weight, nodule number and nodule dry weight of Sesbania sp

\begin{tabular}{|c|c|c|c|c|c|c|}
\hline \multirow{2}{*}{\multicolumn{2}{|c|}{\begin{tabular}{|c|} 
Treatment \\
\multicolumn{2}{|c|}{ Variety $\times$ Inoculation } \\
\end{tabular}}} & $\begin{array}{c}\text { Nitrogen } \\
\text { content }(\%) \text { in } \\
\text { shoot }\end{array}$ & $\begin{array}{l}\text { Shoot dry } \\
\text { weight (mg } \\
\text { plant }^{-1)}\end{array}$ & $\begin{array}{c}\text { Root dry } \\
\text { weight } \\
\text { (mg plant }^{-1)} \\
\end{array}$ & \multirow[t]{2}{*}{$\begin{array}{l}\text { Total nodule } \\
\left(\text { No. }_{\text {plant }}{ }^{-1}\right.\end{array}$} & \multirow[t]{2}{*}{$\begin{array}{l}\text { Nodule dry } \\
\left.\text { weight (mg }^{-1} \text { plant }^{-1}\right)\end{array}$} \\
\hline & & & & & & \\
\hline \multirow{20}{*}{$\begin{array}{c}\text { Deshi } \\
\text { dhaincha }\end{array}$} & DhF1 & $5.15 \mathrm{i}-1$ & 141.30jkl & $32.67 \mathrm{i}-1$ & $26.67 \mathrm{o}$ & $13.07 \mathrm{no}$ \\
\hline & DhF2 & $5.38 \mathrm{~h}-\mathrm{k}$ & 143.30ijk & $26.671 \mathrm{~m}$ & $28.67 \mathrm{mno}$ & 12.07op \\
\hline & DhF3 & $5.66 \mathrm{~d}-\mathrm{j}$ & $162.70 \mathrm{~h}$ & 37.33hij & $33.00 \mathrm{~h}-\mathrm{o}$ & $13.73 n$ \\
\hline & DhF4 & $5.54 \mathrm{e}-\mathrm{k}$ & $164.70 \mathrm{~h}$ & $28.00 \mathrm{kl}$ & $32.33 \mathrm{i}-\mathrm{o}$ & $13.63 n$ \\
\hline & DhM1 & 6.10de & $172.00 \mathrm{fg}$ & $49.33 c-f$ & $46.33 \mathrm{abc}$ & $18.27 \mathrm{kl}$ \\
\hline & DhM2 & $5.99 \mathrm{~d}-\mathrm{g}$ & $176.70 \mathrm{ef}$ & $50.67 c-f$ & $36.00 \mathrm{e}-n$ & $18.07 \mathrm{kl}$ \\
\hline & DhM3 & $6.66 \mathrm{bc}$ & $208.00 \mathrm{a}$ & $70.00 \mathrm{a}$ & $52.00 \mathrm{ab}$ & $26.43 \mathrm{e}$ \\
\hline & DhM4 & $5.54 \mathrm{e}-\mathrm{k}$ & $176.70 \mathrm{ef}$ & $41.33 \mathrm{gh}$ & $40.00 \mathrm{c}-\mathrm{j}$ & $22.33 \mathrm{~h}$ \\
\hline & DhT1 & $5.50 \mathrm{f}-\mathrm{k}$ & 143.30ijk & $30.00 \mathrm{kl}$ & $27.33 \mathrm{no}$ & 11.90op \\
\hline & DhT2 & $5.78 \mathrm{~d}-\mathrm{h}$ & 128.00no & $28.00 \mathrm{kl}$ & 30.001-o & 13.13no \\
\hline & DhT3 & $5.72 \mathrm{~d}-\mathrm{i}$ & $162.70 \mathrm{~h}$ & $31.33 \mathrm{jkl}$ & $36.00 \mathrm{e}-\mathrm{n}$ & $15.93 \mathrm{~m}$ \\
\hline & DhT4 & 6.10de & $161.30 \mathrm{~h}$ & 44.00fgh & $34.67 \mathrm{f}-\mathrm{o}$ & $19.60 \mathrm{ij}$ \\
\hline & DhSk1 & $6.72 b c$ & $191.30 \mathrm{~b}$ & $63.33 b$ & $37.67 \mathrm{c}-1$ & $23.40 \mathrm{gh}$ \\
\hline & DhSk2 & $7.50 \mathrm{a}$ & $176.00 \mathrm{ef}$ & $53.00 \mathrm{c}$ & $42.67 c-f$ & $20.40 \mathrm{i}$ \\
\hline & DhSk3 & $6.05 \mathrm{def}$ & $184.00 \mathrm{~cd}$ & $68.00 \mathrm{ab}$ & $36.00 \mathrm{e}-n$ & $24.67 \mathrm{f}$ \\
\hline & DhSk4 & $5.43 \mathrm{~g}-\mathrm{k}$ & $171.70 \mathrm{fg}$ & $54.67 \mathrm{c}$ & $35.33 \mathrm{e}-\mathrm{o}$ & $18.53 \mathrm{jk}$ \\
\hline & DhP1 & $6.94 b$ & $163.30 \mathrm{~h}$ & $51.33 \mathrm{cde}$ & $36.33 \mathrm{e}-\mathrm{m}$ & $24.93 \mathrm{f}$ \\
\hline & DhP2 & $4.651 \mathrm{~m}$ & $190.00 \mathrm{bc}$ & $62.00 \mathrm{~b}$ & $40.67 c-i$ & $24.27 \mathrm{fg}$ \\
\hline & DhP3 & $5.99 \mathrm{~d}-\mathrm{g}$ & 181.30de & 64.00ab & $35.00 \mathrm{f}-\mathrm{o}$ & $22.73 \mathrm{~h}$ \\
\hline & Control & $4.48 \mathrm{mn}$ & $48.67 \mathrm{~s}$ & $16.67 \mathrm{n}$ & $0.00 \mathrm{p}$ & $00.00 \mathrm{r}$ \\
\hline \multirow{20}{*}{$\begin{array}{c}\text { African } \\
\text { dhaincha }\end{array}$} & DhF1 & $4.11 \mathrm{mno}$ & $94.00 \mathrm{r}$ & $30.00 \mathrm{kl}$ & 29.331-o & $9.25 \mathrm{q}$ \\
\hline & DhF2 & $4.31 \mathrm{mn}$ & $98.67 \mathrm{r}$ & $28.00 \mathrm{kl}$ & $30.67 \mathrm{k}-\mathrm{o}$ & $9.75 q$ \\
\hline & DhF3 & $4.42 \mathrm{mn}$ & $120.30 p$ & $32.00 \mathrm{i}-1$ & $33.33 \mathrm{~g}-\mathrm{o}$ & $15.03 \mathrm{~m}$ \\
\hline & DhF4 & $5.26 \mathrm{~h}-\mathrm{k}$ & 124.70nop & $34.67 \mathrm{ijk}$ & $34.67 \mathrm{f}-\mathrm{o}$ & $13.63 n$ \\
\hline & DhM1 & $5.32 \mathrm{~h}-\mathrm{k}$ & $146.00 \mathrm{ij}$ & $45.33 \mathrm{~d}-\mathrm{g}$ & $42.67 c-f$ & $24.60 \mathrm{fg}$ \\
\hline & DhM2 & $5.70 \mathrm{~d}-\mathrm{i}$ & $140.00 \mathrm{jkl}$ & 44.00fgh & $40.67 c-i$ & $23.00 \mathrm{~h}$ \\
\hline & DhM3 & $5.46 \mathrm{~g}-\mathrm{k}$ & $166.00 \mathrm{gh}$ & $54.67 \mathrm{c}$ & $52.67 \mathrm{a}$ & $36.80 \mathrm{a}$ \\
\hline & DhM4 & $4.31 \mathrm{mn}$ & 138.70jkl & $49.33 c-f$ & $41.33 \mathrm{c}-\mathrm{h}$ & 17.131 \\
\hline & DhT1 & $4.37 \mathrm{mn}$ & $111.30 \mathrm{q}$ & $32.00 \mathrm{i}-1$ & $31.33 \mathrm{j}-\mathrm{o}$ & $11.63 p$ \\
\hline & DhT2 & $4.42 \mathrm{mn}$ & $108.70 q$ & $30.67 \mathrm{jkl}$ & $33.33 g-0$ & 12.10op \\
\hline & DhT3 & $4.48 \mathrm{mn}$ & 121.30op & 44.67efg & $36.67 \mathrm{~d}-\mathrm{m}$ & $20.80 \mathrm{i}$ \\
\hline & DhT4 & $3.64 \mathrm{o}$ & 125.70nop & $32.67 \mathrm{i}-1$ & $35.67 e-n$ & $19.03 \mathrm{jk}$ \\
\hline & DhSk1 & $4.651 \mathrm{~m}$ & $159.30 \mathrm{~h}$ & $50.00 \mathrm{c}-\mathrm{f}$ & $40.67 c-i$ & $31.47 \mathrm{c}$ \\
\hline & DhSk2 & $4.14 \mathrm{mno}$ & $138.00 \mathrm{klm}$ & $51.33 \mathrm{cde}$ & $45.33 a-d$ & $24.87 f$ \\
\hline & DhSk3 & 6.10de & 149.30i & $52.00 \mathrm{~cd}$ & $39.33 c-k$ & $33.33 b$ \\
\hline & DhSk4 & $5.04 \mathrm{kl}$ & $135.301 \mathrm{~m}$ & 44.00fgh & $42.00 \mathrm{c}-\mathrm{g}$ & $32.57 \mathrm{bc}$ \\
\hline & DhP1 & $6.22 \mathrm{~cd}$ & $131.30 \mathrm{mn}$ & 38.67ghi & $35.00 \mathrm{f}-\mathrm{o}$ & $27.73 \mathrm{~d}$ \\
\hline & DhP2 & $4.09 \mathrm{mno}$ & $148.70 \mathrm{i}$ & $48.67 c-f$ & $44.00 \mathrm{~b}-\mathrm{e}$ & $26.93 \mathrm{de}$ \\
\hline & DhP3 & $5.10 \mathrm{jkl}$ & 141.30jkl & $49.33 c-f$ & $39.67 c-j$ & $31.73 c$ \\
\hline & Control & $4.05 \mathrm{no}$ & $42.67 \mathrm{~s}$ & $20.67 \mathrm{mn}$ & $0.00 \mathrm{p}$ & $00.00 \mathrm{r}$ \\
\hline \multicolumn{2}{|c|}{ Significant level } & $1 \%$ & $1 \%$ & $1 \%$ & $1 \%$ & $1 \%$ \\
\hline \multicolumn{2}{|c|}{$C V(\%)$} & 5.52 & 5.52 & 8.33 & 8.33 & 3.60 \\
\hline
\end{tabular}

In a column, figures having similar letter (s) do not differ significantly as per DMRT. 


\section{Performance of rhizobial strains on growth, nodulation and nitrogen fixation of Sesbania sp.}

\section{Nitrogen content in shoot}

Data on nitrogen content in shoot have been presented in Table 01 and 02 . The result showed highly significant effect of rhizobial inoculant, variety and their interaction on nitrogen content in shoot of Sesbania.

Effect of inoculation: Results on the effect of inoculation strains on nitrogen content in Sesbania shoot were highly significant compared to control. The strain DhP1 contained the highest nitrogen (6.58\%) in shoot. Second highest nitrogen in shoot was found in treatments DhSk3 and DhM3. Treatments DhM2 and DhSk2 contained significantly lower nitrogen than DhP1, DhSk3 and DhM3 but higher than the others.

Effect of variety: The effect of varieties on nitrogen content in Sesbania shoot was significant in glass house. Deshi dhaincha contained higher nitrogen (5.84\%) than African dhaincha (4.76\%).

Interaction effect of inoculation $\times$ variety: Result revealed that the interaction effect of inoculants $x$ variety on nitrogen content was significant. However highest content was recorded in variety DhSk2 in Deshi Dhaincha (6.98\%) followed by DhP1 in Deshi Dhaincha (6.94\%).

\section{Shoot dry weight}

The result showed highly significant effect of rhizobial inoculation, variety and their interaction on shoot dry weight of Sesbania have been presented in Table 01 and 02.

Effect of inoculation: The effect of rhizobial inoculation on shoot dry weight of Sesbania was found significant (Table 01). DhM3 the highest shoot dry weight $\left(187 \mathrm{mg}\right.$ plant $\left.^{-1}\right)$ whereas control produced the lowest. DhSk1 produced lower amount (175.30mg plant ${ }^{-1}$ ) than DhM3 and significantly higher than other strains. Hoque (1986) reported significantly higher shoot dry weight due to inoculation with different inoculant strains.

Effect of variety: Shoot dry weight of Deshi dhaincha $\left(162.40 \mathrm{mg} \mathrm{plant}^{-1}\right)$ was significantly higher than African dhaincha (127.10mg plant ${ }^{-1}$ ). Similar result was reported by Anonymous (1998).

Interaction effect of inoculation $\times$ variety: Highest shoot dry weight plant ${ }^{-1}$ was recorded in strain DhM3 in Deshi dhaincha (208mg plant ${ }^{-1}$ ) followed by DhSk1 (191.30mg plant ${ }^{-1}$ ) Deshi dhaincha. Inoculant strains gave significantly higher shoot dry weight over control. The above results were supported with the works of Islam (1999).

\section{Root dry weight}

The results showed significant effect of rhizobial inoculation, variety and their interaction on root dry weight of Sesbania have been presented in Table 01 and 02.

Effect of inoculation: The effect of inoculation on root dry weight (Table 01) showed that DhM3 produced the highest root dry weight $\left(62.33 \mathrm{mg} \mathrm{plant}^{-1}\right)$ whereas control recorded the lowest. The strain DhSk3 produced higher amount of root dry weight $\left(60 \mathrm{mg} \mathrm{plant}^{-1}\right)$ than other strains but lower than DhM3. Hoque (1986) reported significantly higher root dry weight due to inoculation with different inoculant strains.

Effect of variety: The effect of varieties on root dry weight of Sesbania was significant (Table 01). Root dry weight of Deshi dhaincha was significantly higher than African dhaincha in both glass house and open soil condition. Similar result was reported by Anonymous (1998). 
Interaction effect of inoculation $\times$ variety: Interaction effect of inoculants $\times$ variety on root dry weight was significant (Table 02). However highest root dry weight plant $^{-1}$ was recorded in strain DhM3 in Deshi dhaincha (70mg plant $\left.{ }^{-1}\right)$ followed by DhSk3 (68mg plant $\left.{ }^{-1}\right)$ and DhP3 $\left(64 \mathrm{mg} \mathrm{plant}^{-1}\right)$.

\section{Nodule number}

Table 01 and 02 shows inoculation with Rhizobium inoculation increased the total nodule numbers which become statistically significant. Rhizobium inoculation $\times$ variety interaction effects on nodule number were also significant at both the conditions.

Effect of inoculation: Inoculant DhM3 (62.33) recorded the highest nodule number (Table 01). Next to the highest nodule number was showed by DhM1 (44.50). Treatment DhSK2 produced higher nodule than the other strains but significantly lower nodule than DhM3 and DhM1. Sattar et al. (1994) reported that inoculation increased effective nodule and nodule biomass. Vest et al. (1973) reported that Rhizobium strains differ in their ability to induce nodulation.

Effect of variety: Results indicated that the effects of varieties on nodule number were significant (Table 01). African dhaincha recorded higher number of nodule (36.42 plant $^{-1}$ ) than Deshi dhaincha (34.33 plant $\left.^{-1}\right)$.

Interaction effect of inoculation $x$ variety: Result revealed that the interaction effect of inoculants $x$ variety on nodule number of Sesbania was significant. However, highest nodule number plant $^{-1}$ were recorded in DhM3 in both the varieties, African dhaincha (52.67 plant $^{-1}$ ) and Deshi dhaincha (52 plant $^{-1}$ ) followed by DhM1 in Deshi dhaincha (46.33 plant ${ }^{-1}$ ) and DhSk2 in African Dhaincha (45.33 plant $^{-1}$ ). No nodule was found in control in sterile condition. Interaction effect of inoculation $\times$ variety in nodule number was supported by Hoque (1986).

\section{Nodule dry weight}

The results showed highly significant effect of rhizobial inoculation, variety and their interaction on nodule dry weight (Table 01 and 02 ).

Effect of inoculation: The effect of inoculation on nodule dry weight was presented in Table 01. Data showed that DhM3 recorded the highest nodule dry weight $\left(31.62 \mathrm{mg} \mathrm{plant}^{-1}\right)$ where control produced no nodule. The strain DhSk3 recorded statistically higher amount of nodule ( $\left.29 \mathrm{mg} \mathrm{plant}^{-1}\right)$ than other strains but lower than DhM3. Sattar et al. (1994) reported that inoculation increased nodule dry weight. Hoque (1986) reported significantly higher nodule dry weight due to inoculation with different inoculant strains.

Effect of variety:Result showed that the effects of variety on nodule dry weight of Sesbania were significant (Table 01). Nodule dry weight of African dhaincha $\left(21.07 \mathrm{mg} \mathrm{plant}^{-1}\right)$ was significantly higher than Deshi dhaincha (18.85mg plant ${ }^{-1}$ ).

Interaction effect of inoculation $\times$ variety: Results revealed that the interaction effect of inoculants $\times$ variety on nodule dry weight of Sesbaniawere significant (Table 02). The highest nodule dry weight plant $^{-1}$ was recorded in strain DhM3 in African dhaincha $\left(36.80 \mathrm{mg}^{-1 a n t^{-1}}\right.$ ) followed by DhSk3 (33.33 $\mathrm{mg} \mathrm{plant}^{-1}$ ) and DhSk4 (32.57mg plant ${ }^{-1}$ ) in African dhaincha. No nodule was found in control. 


\section{Conclusion}

All the strains increased nitrogen content of shoot, shoot dry weight, root dry weight, nodule number and nodule dry weight of Sesbania cultivars in glass of Deshi dhaincha (Sesbania aculeata) and African dhaincha (Sesbania rostrata) plants. The strain DhM3 produced the highest nitrogen content of shoot, shoot dry weight, root dry weight, nodule number and nodule dry weight. The strain DhSk2 ranked second and DhSk4 ranked third. So, the strains DhM3, DhSk2 and DhSk4 may be selected for producing inoculant for cultivation of Dhaincha in examined AES's. But conclusions and perspectives are valid under the present experimental conditions. Further experiments are needed to be conducted in soils of different AEZ's having wide variations in soil $\mathrm{pH}$, organic matter and nutrient status for confirmation of the findings.

\section{Acknowledgement}

From the core of heart, the author expresses his deep sense of gratitude, sincere appreciation to Soil Microbiology Laboratory, Soil Science Division, Bangladesh Institute of Nuclear Agriculture (BINA), Mymensingh. The author also extends his cordial thanks to his friends and well-wishers who always inspired him with best of their wishes to complete this manuscript.

\section{References}

Anonymous. (1998). Response of lentil, chickpea and soybean to rhizobial and chemical fertilizers. Annual reports, BINA, 1996-97. pp. 165-169.

Athar, M. (1998). Drought tolerance of lentil rhizobia (Rhizobium leguminosarum) from arid and semi arid areas of Pakistan. Lett. Appl. Micobiol. 26: 38-42.

Azam, F. (2001). Legume-bacterium (Rhizobium) association symbiosis, a marriage of convenience, necessary evil or bacterium taken hostage by the legume. Pakistan J. Biol. Sci. 4: 757-761.

Brockwell, J. and Bottomol, R. S. (1995). Recent advances in inoculant technology and prospects for the future. Soil Biol. Biochem. 27: 683-697.

Freiberg, C. K., Fellay, A., Bairoch, W. J., Broughton, A., and X. Perret. (1997). Molecular basis of symbiosis between Rhizobium and legumes. Nature, 1997. 387: 394-401.

Gomez, K. A. and Gomez, A. A. (1984). Statistical Procedures for Agricultural Research. 2nd Ed. Wiley Interscience Publication. John Wiley and Sons. p: 207-215.

Gopalakrishnan, S. and Grish, A. G. (1999). Physiological and biochemical characteristics of fast growing rhizobia of Sesbania bispinosa in the in vitro condition. Legume Res. 22(4); 227-232.

Hardarson, G. (1993). Method for enhancing symbiotic nitrogen fixation. Plant and Soil. 152: 1-17.

Hoque. M. S. (1986). Biological nitrogen fixation studies in soybean and groundnut. Paper presented in the BAURES workshop on "BAU Research Progress" held on 4 -5 October, 1986. pp. 5381.

Jefing, Y, Herridge, D. F., Peoples, M. B. and Rerkasem, B. (1992). Effects of N fertilization on N2 fixation and $\mathrm{N}$ balance of soybean grown after lowland rice. Plant and Soil, 147: 235-242.

Jensen, H. L. (1942). Nitrogen fixation in leguminous plants. General characters of root nodule bacteria isolated from species of Medicago and Trifolium in Australia, Proc. Linn. Soc., N.S.W., 66: 98-108.

Lshizuka, J. (1992). Trends in biological nitrogen fixation research and application. Plant and Soil. 141:197-209. 
Sattar, M. A. and Podder, A. K. (1994). Single strain vs. multistrain inoculation: Field response of groundnut to Bradyrhizobium strains under different agro-ecological region of Bangladesh. Extended Synopsis 15th Inter. Cong. Soil Sci. Poster, Commission III. Symposium 11b, July 10-16 held at Acapulco, Mexico. Vol. 4b.

Shah, N. H., Hafeez, F. Y., Hussain, A. and Malik, K. A. (2000). Response of lentil to nitrogen and phosphorus fertilizer and inoculation with Rhizobium leguminosarum by vicea strains. Aust. J. Expert. Agri. 40: 93-98.

Shishidu, M. and Pepper, I. L. (1990). Identification of dominant indigenous Rhizobium merlilotic by plasmid profiles and intrinsic antibiotic resistance. Soil Biol. Biochem. 22: 11-16.

Vest, G., Weber, F. L. and Sloges, C. (1973). Nodulation and nitrogen fixation, "In soybean improvement production and uses" (Caldwell, B.C.ed.) USA Monograph 16, Amer. Soc. Agron. Inc. Publisher, Madison, Wisconsin, USA, p: 353-390.

\section{Citation for this article (APA Style):}

Hasan, M. Z., Alam, M. S., Mian, M. H. \& Islam, M. Z. (2015). Isolation, Characterization and Selection of Rhizobium Strains for Cultivation of Sesbania sp. Journal of Bioscience and Agriculture Research, 03(02), 79-86.

Retrieved March 18, 2015 from http://www.journalbinet.com/jbar-volume-03-issue-01.html 